\title{
ON THE PENETRATION OF ROCK BY THREE-DIMENSIONAL INDENTORS
}

\author{
M. H. MiLLER \\ Space Systems Division, AVCO Corporation, Lowell, Mass. \\ and \\ D. L. SIKARSKIE \\ Department of Aerospace Engineering, University of Michigan \\ (Received 1 February 1968)
}

\begin{abstract}
An experimental and theoretical investigation was undertaken of the rock-penetrating characteristics of five statically loaded, three-dimensional indentors; two cones, two spheres and a pyramid. Two rock types were used in the study, Barre granite and Indiana limestone.

The indentors are compared on the basis of the forces necessary to penetrate to a given distance by crushing, the stress required to cause chipping, and the amount of energy required to fracture a unit volume of rock. In addition the indentor results are compared to some wedge results obtained under identical conditions.

In order to gain some insight into the penetration of rock by three-dimensional indentors, the two-dimensional static penetration theory of Paul and Sikarskie has been extended in this report to three-dimensional indentors.
\end{abstract}

\section{INTRODUCTION}

ONE of the purposes of the experimental program described herein was to isolate the trends which characterize three-dimensional indentors and find how they differ from two-dimensional indentors such as wedges. In particular it is desirable to obtain trends in the specific fracture energy (energy necessary to excavate a unit volume of rock) and in the crushing and chipping characteristics of the indentors since these are important factors in such processes as rock drilling.

In order to determine the influence of indentor bluntness, conical indentors were compared to spherical indentors. The effects of secondary stress concentrations were investigated by using pyramid indentors which develop stress concentrations at the edges. In all, five indentors were used: Two cones, two spheres and a pyramid. These indentors are shown in Fig. 1.

The influence of rock strength was studied by using a medium-strength rock, Indiana limestone; and a relatively strong rock, Barre granite. The effect of bedding plane orientation was also studied in the limestone.

The second general purpose of this program was to provide a background of experience necessary for the formation of a theory which can describe the penetration of three-dimensional indentors into rock. Based upon previous work of PAUL and SiKarSKIE[1], an attempt has been made in Section 4 of this paper to develop such a theory.

Finally, this program has provided numerical data relating to three-dimensional indentors which should be useful in future design and research work. Although there is some information in the literature relating to dynamic (drop tower) indentation of rock by threedimensional indentors-see, for instance, references [2] and [3] - the present authors have 


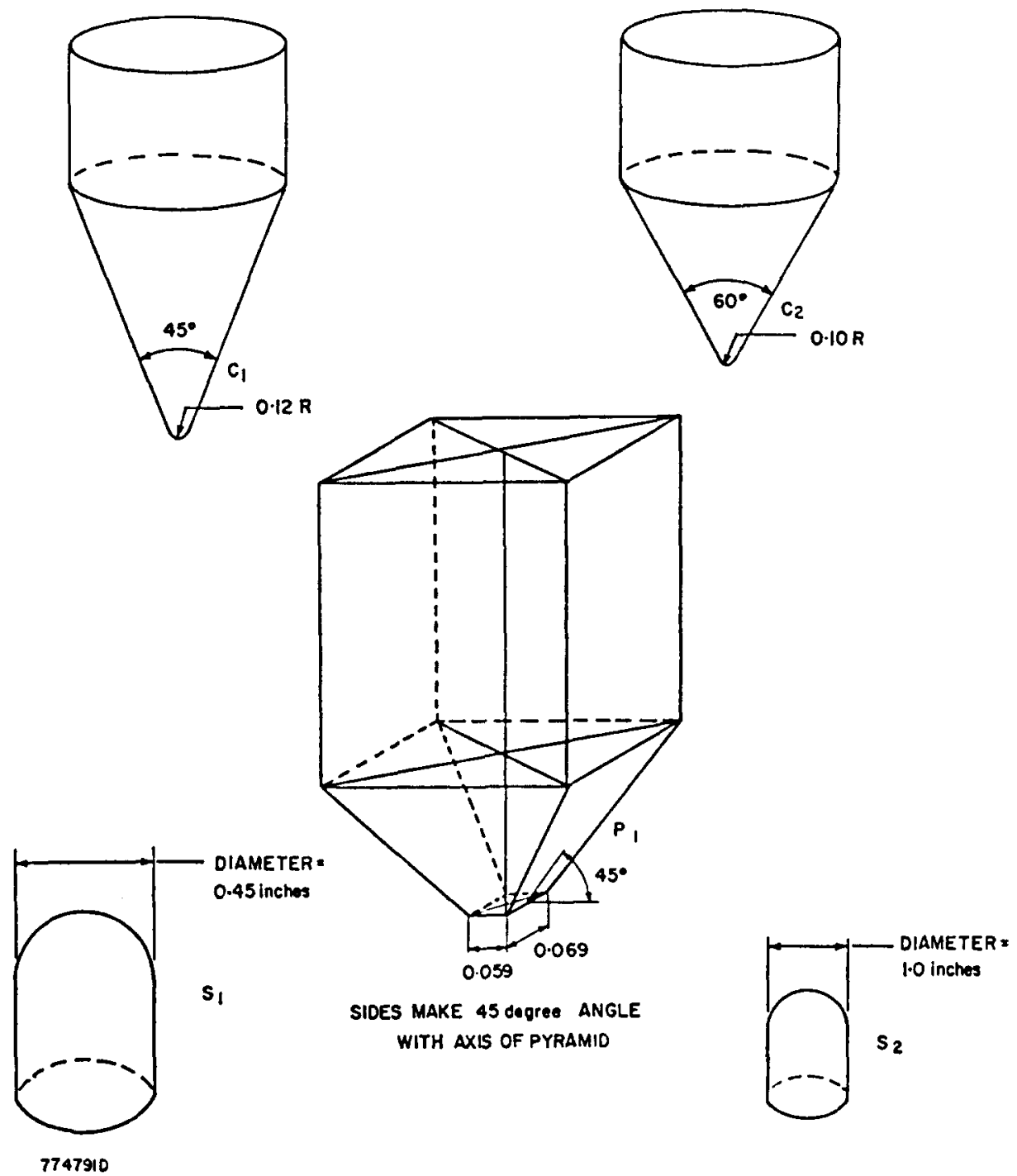

Fic. 1. Indentors.

been unable to find previous pertinent results relating to the penetration of these indentors under a static load. The advantage of a static loading is that the details of the formation of the crater can be observed and recorded.

The experimental equipment used in the project is described in Section 2 of this paper. The experimental results are presented in Section 3. The extension of the two-dimensional theory to three dimensions is given in Section 4, and the authors' conclusions are presented in Section 5.

\section{EXPERIMENTAL APPARATUS}

Figure 2 is a schematic representation of the complete experimental set-up. In brief, the system worked as follows; the ram forced the indentor, to which it was rigidly attached, 
into the rock sample quasi-statically. The load cell experienced the same total load as the wedge since they were mounted in series. The electrical signal corresponding to this load was fed into the $Y$-axis of an $X-Y$ recorder. Two Linear Variable Differential Transformers (L.V.D.T.'s), held on arms of equal length extending from the wedge holder, produced a signal proportional to the displacement of the descending ram. These signals were summed to cancel rotational effects and the calibrated sum was then fed into the $X$-axis of the recorder. This resulted in a continuous graphical plot of force versus displacement. Some of the details of the experimental set-up are elaborated upon below.

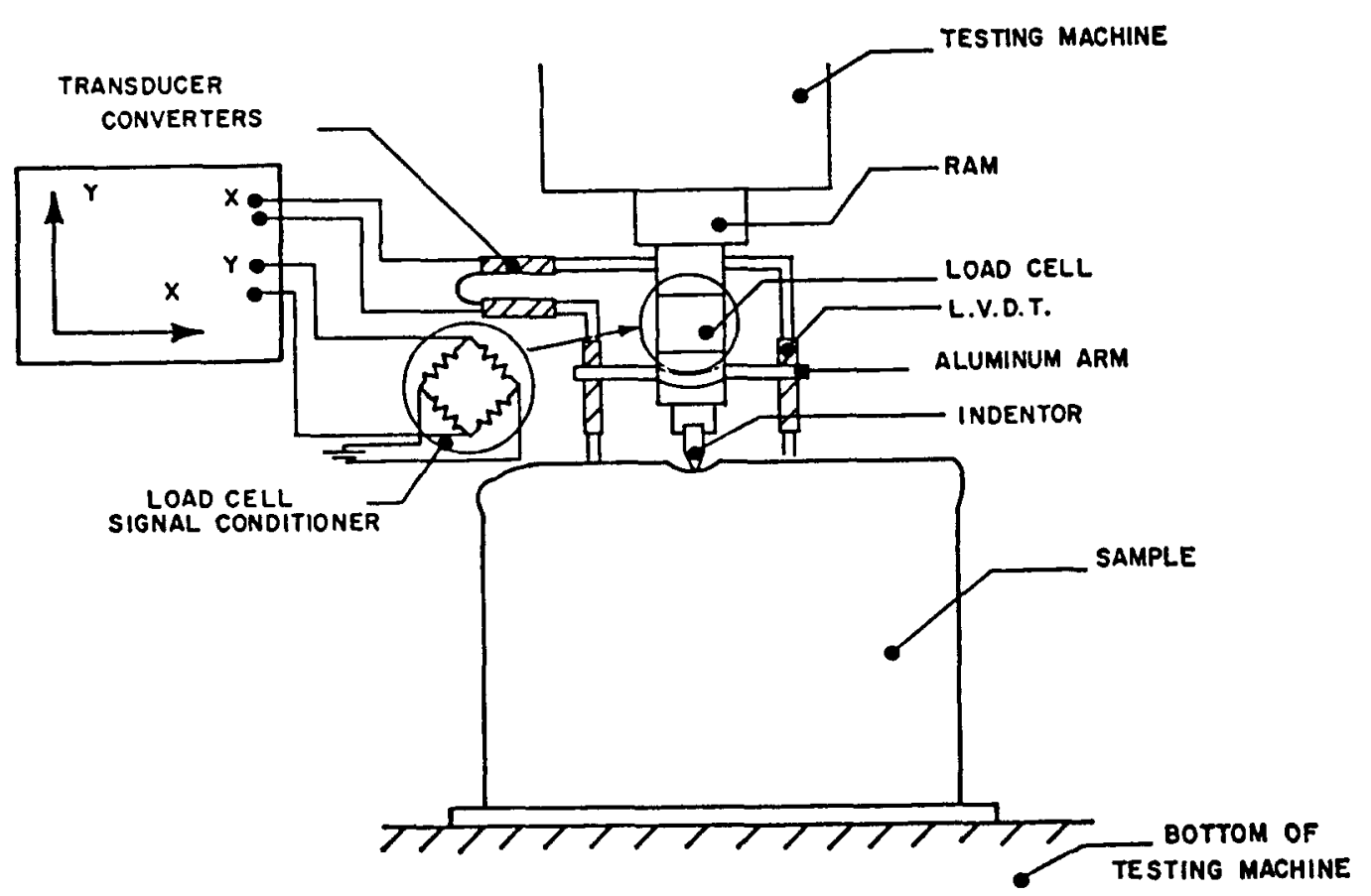

FiG. 2. Schematic of experimental set-up.

The load cell used to measure the total force on the indentor was constructed in-house and consisted of a cylindrical steel tube with a 2 in. outside diameter, 3 in. length, and a 1 in. wall thickness. Eight strain gages were attached to this cylinder, four in the longitudinal direction and four in the Poisson direction. The gages were attached in pairs oriented $90^{\circ}$ apart and were connected to form a four arm, $240 \Omega$ bridge.

The bridge power was supplied by a $0-25 \mathrm{~V}, 200 \mathrm{~mA}$ power supply operating at $10 \mathrm{~V}$. A signal conditioner which had a bridge voltage adjustment, calibrating switch, and a nulling circuit, was used to condition the signal from the bridge. The calibrated output signal from this conditioner was fed directly into the $Y$-axis of a Moseley (7030A) $X-Y$ recorder.

The force on the wedge was supplied by a Soil Test 400,000 -lb capacity compression machine. 
Two L.V.D.T.'s were used to measure penetration. Each unit was used in conjunction with a transducer converter which supplied the L.V.D.T. with $15 \mathrm{~V}$ at an excitation frequency of $5000 \mathrm{cps}$. The L.V.D.T.'s were mounted at equal distances ( $\$$ in.) from the centerline of the holder on a rigid aluminum arm to minimize dynamic effects at chip formation.

The signals from the two L.V.D.T.'s were added to eliminate the effects of rotation, the 'summed' sensitivity being established by a calibration test. The resultant signal was fed directly into the $X$-axis of the $X-Y$ recorder.

Five indentors were used in these experiments: Two cones, two spheres and a pyramid. The first cone, $C_{1}$, had a semivertex angle of $22 \cdot 5^{\circ}$. Its apex was rounded off to a radius of 0.120 in. The second cone, $C_{2}$, had a semivertex angle of $30^{\prime}$ with its tip rounded off to $0.100 \mathrm{in}$. The two spheres, $S_{1}$ and $S_{2}$, had radii of $0.225 \mathrm{in}$. and $0.500 \mathrm{in}$. respectively. The sides of the pyramid indentor, $P_{1}$, made an angle of $45^{\circ}$ with the axis of the indentor. This indentor was capped by a flat which measured 0.059 in. by $0.069 \mathrm{in}$.

Indentors $C_{1}, C_{2}, S_{1}$ and $P_{1}$ were manufactured of tungsten carbide, indentor $S_{1}$, being very similar to the 'buttons' used in the new button rock drill bits. Indentor $S_{\mathrm{d}}$ was a highstrength steel sphere of the type usually found in ball bearings. As noted previously, the indentors are shown in Fig. 1. The holders used to connect the indentors to the ram assembly were manufactured from a heat-treated tool steel.

Two types of rock were used: Indiana limestone and Barre granite. The Indiana limestone samples were cubes 12 in. on a side with sawed (but fairly smooth) surfaces. The Barre granite was also approximately $12 \mathrm{in}^{3}$, and had one polished face on which the indentations were made.

The testing pattern on any work face was fairly random except for maximum penetration which was specified approximately prior to each test. An attempt was made to keep all deep tests near the center of the sample since some difficulty was encountered with samples splitting when tests were conducted near the edges.

Crater volumes were measured by the burette technique. Craters were first brushed clean with a wire brush and then coated with a silicon oil which prevented the soaking of liquid due to rock porosity. The liquid itself consisted of a 1 per cent Aerosol OT solution (for reducing surface tension) and Methylene Blue dye. The crater was carefully filled with this solution by means of a $1 \mathrm{ml}$ or $5 \mathrm{ml}$ burette depending on crater size. The filled level was determined by eye with the aid of a magnifying glass and a fixed pointer arrangement. The crater was then emptied, dried and the process repeated several times in order to obtain a reliable average.*

The energy expended in each test is the area under the force-penetration curve. This area was measured using a planimeter. The ratio of the expended energy to the crater volume is the specific fracture energy, which is the energy required to break out a unit volume of rock.

\section{EXPERIMENTAL RESULTS}

In the course of this experimental program a total of 172 tests were conducted using the five indentors described in the previous section. These tests were conducted on Barre granite and Indiana limestone, the latter being sub-divided into tests perpendicular and

\footnotetext{
- A given observer could, with some practice, obtain very reproducible results. However, a different observer could obtain a different set of self-consistent results differing by as much as 20 per cent. All tests reported here were measured by the same observer.
} 
parallel to the bedding plane of the rock. The uniaxial compressive strengths of these materials were determined in an additional series of tests conducted by the authors and the values, averaged over a number of tests, are presented in Table 1.

TABLE 1

\begin{tabular}{lccc}
\hline \multicolumn{1}{c}{ Rock type } & Symbol & $\begin{array}{c}\text { Compressive strength } \\
\text { Sample ends } \\
\text { unlubricated }\end{array}$ & $\begin{array}{c}\text { Sample ends } \\
\text { lubricated }\end{array}$ \\
\hline Indiana limestone, normal to bedding plane & I.L. $(\perp)$ & 11,400 & 7300 \\
Indiana limestone, parallel to bedding plane & I.L. $(\|)$ & 9500 & - \\
Barre Granite & B.G. & 28,000 & 24,600 \\
\hline
\end{tabular}

Each indentor was tested on each of these rocks at three different penetrations spanning the range of 0.025 to 0.150 in. A minimum of three tests were conducted for each indentor, at each of three or more penetrations depths.

In general, the results of the experimental program exhibited a great deal of scatter. It was therefore decided to utilize statistical analyses of the results. Thus, most results presented in this section will include mean and median values, the coefficient of variation (ratio of the standard deviation to the mean $\times 100$ ), and the number of tests in the sampling.

\section{Force-pcnetration curves}

The general nature of the force-penetration curves was approximately the same for all five indentors. Typical curves are shown in Figs. 3 and 4.

Figure 3 represents penetrations into limestone. The curve $I$ in this figure is a record of

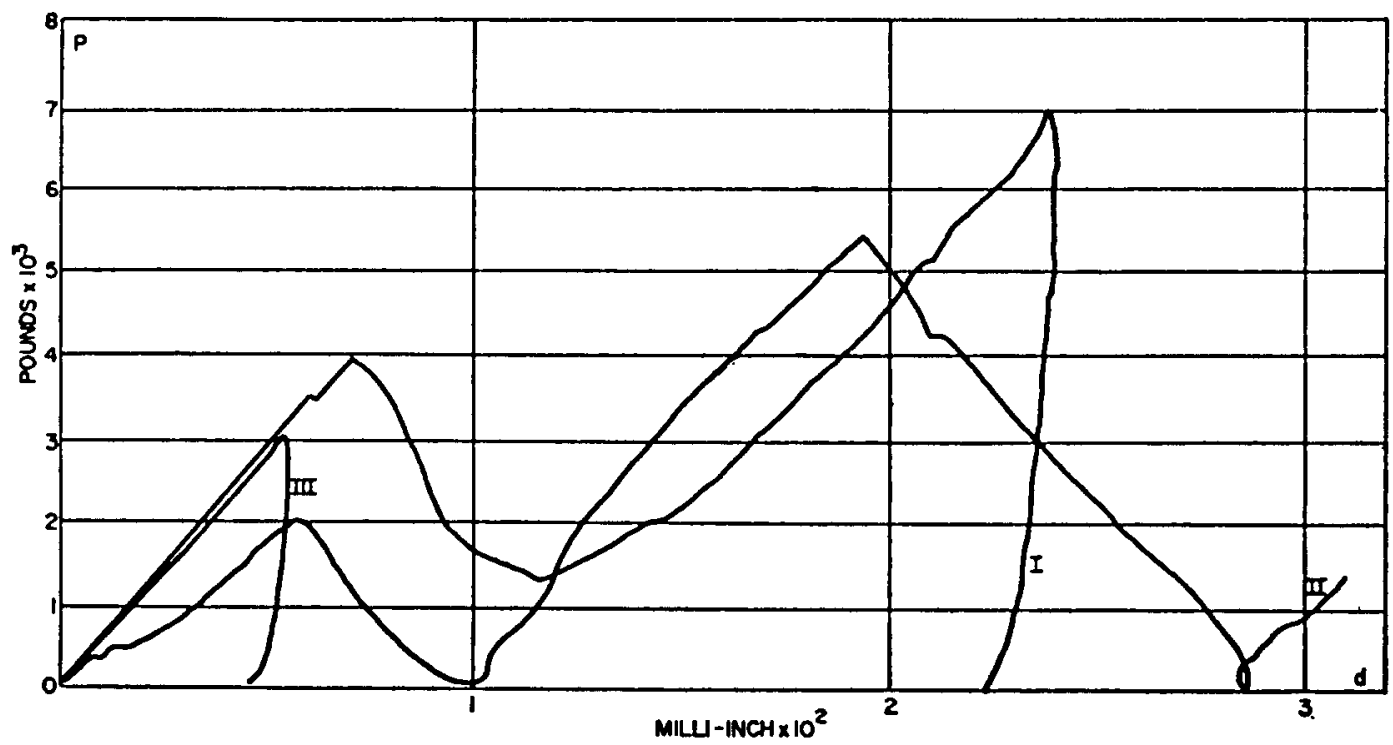

FIG. 3. Force vs. penetration-indentation of Indiana Limestone by $S_{1}$ and $C_{1}$. 
the penetration of sphere $S_{1}$. The initial linear crushing region is climaxed by the formation of a chip and the partial unloading of the indentor. A second crushing phase follows which continues until the completion of the test. Although the slopes of the two crushing phases seem to be approximately the same in this figure, such was not the usual case as is seen in curve II of this figure which represents indentor $C_{1}$ penetrating limestone. In this test the post-chipping crushing slope is greater than the initial crushing slope. It is also noted that the load on the indentor essentially vanished after each chip in this test.

Many of the tests in the limestone produced no chipping at all. A typical example is curve III of Fig. 3 which is again $S_{1}$ penetrating limestone.

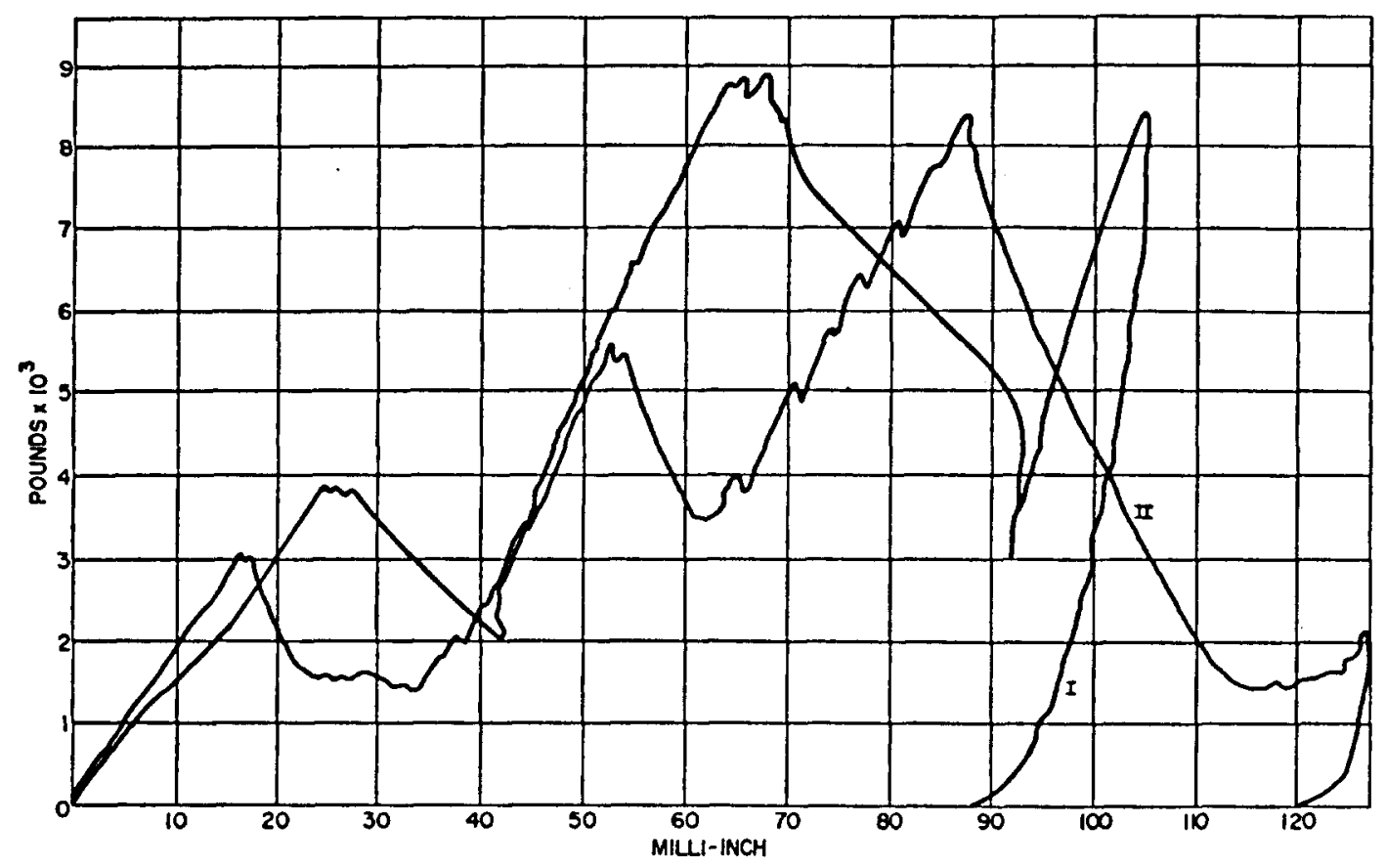

FIG. 4. Force vs. penetration-indentation of Barre Granite by $C_{2}$.

The tests on Barre granite produced curves such as those in Fig. 4 which were both made by the cone, $C_{2}$. In both of these cases there are changes in the slopes of the crushing phases after each chip is formed.

\section{Initial crushing slopes $\left(k_{0}\right)$}

The slope of the force-penetration curve during the crushing phase of penetration, besides being important in understanding the penetration process, is also a necessary input to both the two-dimensional theory of PAUL and SIKARSKIE[1] and the present theory (see Section 4). It is also of some interest to see how this slope varies for later crushing cycles. The initial crushing slope data (before any chips have been formed) is presented in Table 2. 
TABLE 2. INTTIAL CRUSHING SLOPE $\left(k_{a}\right)$

\begin{tabular}{|c|c|c|c|c|c|c|}
\hline Indentor & $\begin{array}{c}\text { Axis of } \\
\text { penetration }\end{array}$ & $\begin{array}{c}\text { Rock } \\
\text { type }\end{array}$ & $\begin{array}{c}\text { Mean } \\
(\mathrm{lb} / \mathrm{m}-\mathrm{in.} .)\end{array}$ & $\begin{array}{c}\text { Median } \\
\text { (lb/m-in.) }\end{array}$ & $\begin{array}{l}\text { Coeff. } \\
\text { variation }\end{array}$ & $\begin{array}{c}\text { Number } \\
\text { of tests }\end{array}$ \\
\hline $\begin{array}{l}C_{1} \\
C_{1} \\
C_{1} \\
C_{1} \\
C_{2} \\
C_{2} \\
C_{2} \\
C_{2} \\
S_{1} \\
S_{1} \\
S_{1} \\
S_{1} \\
S_{2} \\
S_{2} \\
S_{2} \\
S_{2} \\
P_{1} \\
P_{1} \\
P_{1} \\
P_{1}\end{array}$ & $\begin{array}{c}\frac{1}{\|} \\
\text { Both } \\
\text { Both } \\
\frac{1}{\|} \\
\text { Both } \\
\text { Both } \\
\frac{1}{\|} \\
\text { Both } \\
\text { Both } \\
\frac{1}{\|} \\
\text { Both } \\
\text { Both } \\
\frac{1}{\|} \\
\text { Both } \\
\text { Both }\end{array}$ & $\begin{array}{l}\text { IL } \\
\text { IL } \\
\text { IL } \\
\text { BG } \\
\text { IL } \\
\text { IL } \\
\text { IL } \\
\text { BG } \\
\text { IL } \\
\text { IL } \\
\text { IL } \\
\text { BG } \\
\text { IL } \\
\text { IL } \\
\text { IL } \\
\text { BG } \\
\text { IL } \\
\text { IL } \\
\text { IL } \\
\text { BG }\end{array}$ & $\begin{array}{c}26 \cdot 1 \\
23 \cdot 1 \\
24 \cdot 7 \\
186 \cdot 0 \\
25 \cdot 0 \\
33 \cdot 6 \\
28 \cdot 9 \\
172 \cdot 0 \\
54 \cdot 2 \\
54 \cdot 3 \\
54 \cdot 3 \\
374 \cdot 0 \\
106 \cdot 8 \\
93 \cdot 1 \\
100 \cdot 6 \\
583 \cdot 0 \\
21 \cdot 7 \\
36 \cdot 3 \\
28 \cdot 06 \\
285 \cdot 01\end{array}$ & $\begin{array}{r}22 \cdot 1 \\
23 \cdot 8 \\
22 \cdot 7 \\
199 \cdot 0 \\
25 \cdot 0 \\
31 \cdot 9 \\
28 \cdot 2 \\
169 \cdot 0 \\
52 \cdot 8 \\
54 \cdot 5 \\
54 \cdot 4 \\
378 \cdot 0 \\
109 \cdot 3 \\
96 \cdot 4 \\
100 \cdot 7 \\
584 \cdot 0 \\
20 \cdot 0 \\
38 \cdot 3 \\
22 \cdot 7 \\
282 \cdot 33\end{array}$ & $\begin{array}{l}41 \\
11 \\
33 \\
14 \cdot 1 \\
14 \\
21 \\
23 \cdot 9 \\
6 \cdot 9 \\
18 \\
11 \\
15 \cdot 4 \\
6 \cdot 4 \\
7 \cdot 6 \\
9 \cdot 1 \\
10 \cdot 7 \\
05 \\
35 \\
40 \\
47 \\
29 \cdot 2\end{array}$ & $\begin{array}{r}12 \\
10 \\
22 \\
9 \\
11 \\
9 \\
20 \\
9 \\
14 \\
13 \\
27 \\
9 \\
11 \\
9 \\
20 \\
13 \\
13 \\
10 \\
23 \\
9\end{array}$ \\
\hline
\end{tabular}

The mean values of these slopes are presented in Fig. 5. The straight lines connecting the averaged data points in this figure are not meant to imply a continuous relationship, but rather to aid in comparing the five indentors. The results indicate that the spherical indentors require a greater load than the pyramid, which in turn may require a slightly greater

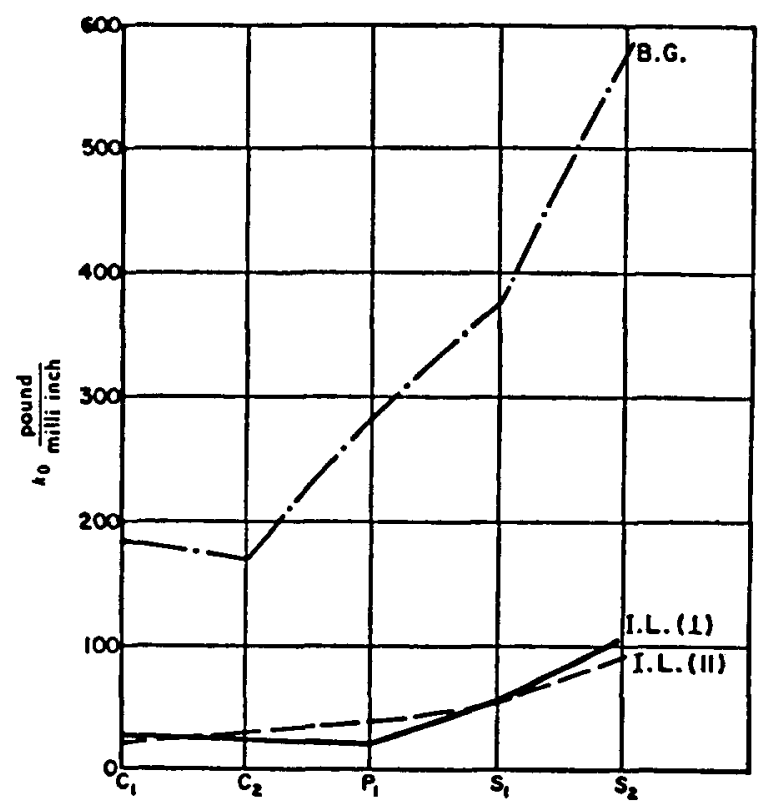

Fio. S. Initial crushing slope. 
load than the cones, to penetrate to a given distance during the crushing phase. It is also seen that the granite is more difficult to crush than limestone parallel to the bedding plane which in turn is generally more difficult to crush than limestone $(\perp)$ normal to the bedding plane.

\section{Post-chipping crushing slopes $\left(k_{1}\right)$}

As there were not a sufficient number of multiple chipping tests to permit a statistical analysis of crushing slopes after the second or third chip, the averages of all post-chipping tests were compiled and are presented in Table 3.

TABle 3. Post-Chipping CRUShING SLOPE $\left(k_{1}\right)$

\begin{tabular}{|c|c|c|c|c|c|c|}
\hline Indentor & $\begin{array}{l}\text { Axis of } \\
\text { penetration }\end{array}$ & $\begin{array}{c}\text { Rock } \\
\text { type }\end{array}$ & $\begin{array}{c}\text { Mean } \\
\text { (lb/m-in.) }\end{array}$ & $\begin{array}{c}\text { Median } \\
\text { (lb/m-in.) }\end{array}$ & $\begin{array}{l}\text { Coeff. } \\
\text { variation }\end{array}$ & $\begin{array}{l}\text { Number } \\
\text { of tests }\end{array}$ \\
\hline$C_{1}$ & $\perp$ & IL & $45 \cdot 1$ & $44 \cdot 2$ & 23 & 5 \\
\hline$C_{1}$ & \| & IL & $36 \cdot 62$ & - & - & 2 \\
\hline$C_{1}$ & Both & IL & $42 \cdot 7$ & $43 \cdot 4$ & 22 & 7 \\
\hline$C_{1}$ & Both & BG & $212 \cdot 0$ & $215 \cdot 0$ & 15 & 6 \\
\hline$C_{2}$ & 1 & IL & $103 \cdot 0$ & - & - & 1 \\
\hline$C_{1}$ & $\|$ & IL & $66 \cdot 24$ & - & - & 2 \\
\hline$C_{2}$ & Both & IL & $78 \cdot 49$ & $76 \cdot 0$ & $24 \cdot 3$ & 3 \\
\hline$C_{2}$ & Both & BG & $237 \cdot 0$ & $237 \cdot 0$ & $15 \cdot 3$ & 7 \\
\hline$S_{1}$ & $\perp$ & IL & $48 \cdot 4$ & $47 \cdot 7$ & $25 \cdot 5$ & 4 \\
\hline$s_{1}$ & $\pi$ & IL & $138 \cdot 7$ & - & - & 2 \\
\hline$s_{1}$ & Both & IL & $78 \cdot 8$ & $60 \cdot 6$ & $61 \cdot 9$ & 6 \\
\hline$s_{1}$ & Both & BG & $374 \cdot 0$ & 393.0 & $37 \cdot 2$ & 5 \\
\hline$S_{3}$ & $\perp$ & IL & $63 \cdot 8$ & - & - & 1 \\
\hline$S_{2}$ & $\pi$ & IL & - & - & - & None \\
\hline$S_{2}$ & Both & II & $63 \cdot 8$ & - & - & 1 \\
\hline$S_{3}$ & Both & IBG & $544 \cdot 0$ & $507 \cdot 0$ & $36 \cdot 3$ & 6 \\
\hline$P_{1}$ & $\perp$ & IL & $47 \cdot 1$ & $40 \cdot 3$ & $29 \cdot 3$ & 4 \\
\hline$P_{1}$ & $\|$ & IL & $60 \cdot 6$ & - & - & i \\
\hline$P_{1}$ & Both & IL & $49 \cdot 8$ & $42 \cdot 1$ & 27 & 5 \\
\hline$P_{1}$ & Both & BG & $197 \cdot 18$ & $209 \cdot 66$ & $41 \cdot 5$ & 8 \\
\hline
\end{tabular}

The mean values of these slopes, almost all of which occurred after one chip, are presented in Fig. 6. Again, it is seen that the spheres exhibit a larger slope than the pyramid or the cones. The values for the pyramid now seem to be lower than those for the larger angle cone, $C_{2}$. It should be noted that the point for $C_{2}$ penetrating limestone perpendicular to the bedding plane has not been plotted since there was only one data point for this condition and that single point, indicated by the flagged point of Fig. 6 , is obviously in error.

Comparing Figs. 5 and 6 , it is seen that the post-chipping crushing slope is generally larger than the initial slope in limestone, but the results are mixed in the granite, where only the conical indentors exhibited a larger post-chipping slope. The relative crushing hardness of the rocks seems to be preserved as the post-chipping crushing slopes for granite are also larger than parallel limestone which is larger than that for perpendicular limestone. The post-chipping crushing slope is the more realistic value from the point of view of rock drilling since the indentor is now penetrating a previously chipped surface. 


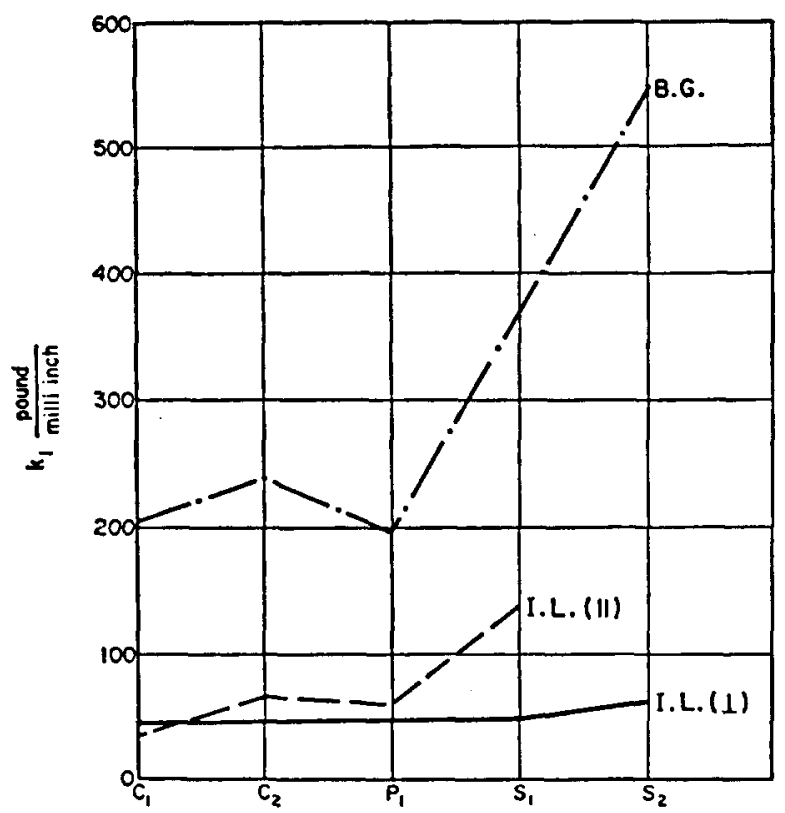

FIc. 6. Post-chipping crushing slope.

\section{Specific fracture energy}

Attempts to experimentally establish a relationship between specific energy and depth of penetration were given up in the face of the large scatter exhibited by the data. A certain amount of scatter is to be expected, however, due to the chipping behavior, i.e. the volume removed is a discontinuous function at chip formation while the energy is continuous. Thus at chip formation we expect a sudden drop in specific energy. Within this expected scatter-band there appeared to be no dependence on penetration depth for the depths considered. A typical plot of specific energy vs. penetration is shown in Fig. 7 which is a

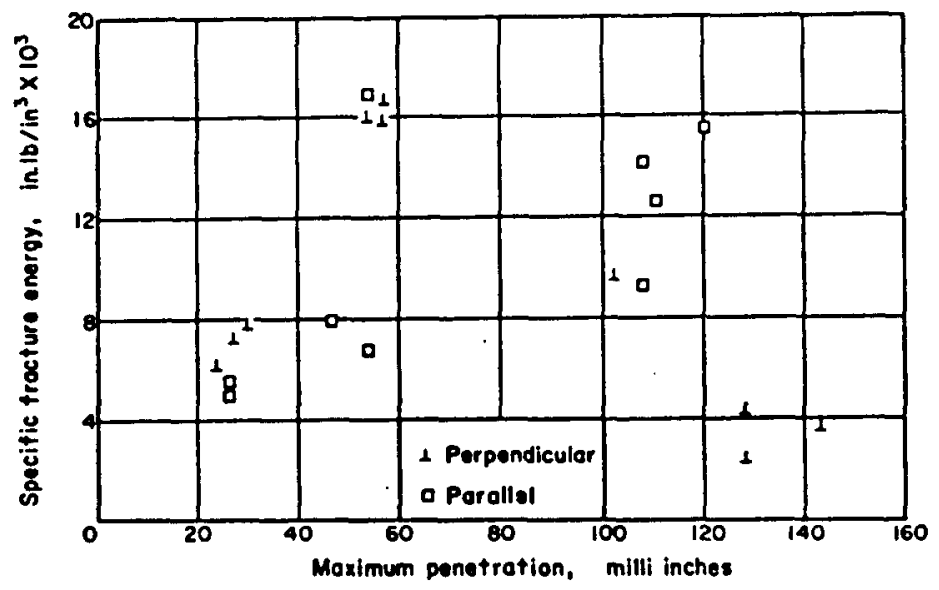

Fig. 7. Specific fracture energy vs. penetration. (Typical plot.) 
record of $S_{2}$ indenting limestone. It was therefore decided to include data at all penetration depths in our statistical sample period. The results are presented in Table 4 and Fig. 8.

The large coefficients of variation associated with these data are due to four sources of scatter in addition to that already mentioned. First, the critical stresses needed to cause either crushing or chipping are random functions of space as indicated by Tables 2, 3 and 5 . Second, the amount of rock broken out in any one crushing or chipping phase is dependent upon such factors as the presence of incipient cracks, and so this, too, is a random function of space. Third, a certain amount of scatter is introduced by the crater cleaning and crater volume measurement techniques, as both involve somewhat arbitrary criteria as was discussed in Section 2. Lastly, there is the error involved in finding the energy

TABLE 4. SPECIFIC FRACTURE ENERGY

\begin{tabular}{|c|c|c|c|c|c|c|}
\hline Indentor & $\begin{array}{c}\text { Axis of } \\
\text { penetration }\end{array}$ & $\begin{array}{c}\text { Rock } \\
\text { type }\end{array}$ & Mean (psi) & Median (psi) & $\begin{array}{c}\text { Coeff. } \\
\text { variation }\end{array}$ & $\begin{array}{l}\text { Number } \\
\text { of tests }\end{array}$ \\
\hline$C_{1}$ & $\perp$ & IL & 2387 & 2565 & $36 \cdot 9$ & 10 \\
\hline$C_{1}$ & $\pi$ & IL & 3745 & 3614 & $20 \cdot 6$ & 8 \\
\hline$C_{1}$ & Both & IL & 2990 & 3038 & $35 \cdot 9$ & 18 \\
\hline$C_{1}$ & Both & BG & 21,175 & 17,415 & $40 \cdot 5$ & 9 \\
\hline$C_{1}$ & + & IL & 3007 & 2583 & $59 \cdot 8$ & 7 \\
\hline$C_{3}$ & 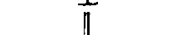 & IL & 9496 & 7749 & 51.9 & 9 \\
\hline$c_{3}^{2}$ & Both & IL & 6657 & 6364 & $75 \cdot 8$ & 16 \\
\hline$C_{3}$ & Both & BG & 24,448 & 22,986 & $28 \cdot 7$ & 9 \\
\hline$S^{3}$ & 1 & IL & 6286 & 5692 & $44 \cdot 2$ & 13 \\
\hline$S_{1}$ & $\stackrel{1}{\|}$ & IL & 10,186 & 8632 & $50 \cdot 0$ & 9 \\
\hline$S_{1}$ & Both & IL & 7881 & 6997 & 55.1 & 22 \\
\hline$S_{1}$ & Both & BG & 25,904 & 25,995 & $26 \cdot 9$ & 9 \\
\hline$S_{2}$ & $\perp$ & IL & 8963 & 7389 & $56 \cdot 8$ & 10 \\
\hline $\begin{array}{l}S_{2} \\
S_{3}\end{array}$ & $\|$ & IL & 10,353 & 9211 & $41 \cdot 0$ & 9 \\
\hline$S_{3}$ & Both & IL & 9622 & 7929 & $49 \cdot 4$ & 19 \\
\hline $\begin{array}{l}S_{2} \\
S_{2}\end{array}$ & Both & BG & 24,247 & 21,694 & $37 \cdot 7$ & 7 \\
\hline$\hat{p}_{1}$ & 1 & IL & 4084 & 4163 & $49 \cdot 3$ & 12 \\
\hline$P$ & $\frac{1}{\|}$ & IL & 11,051 & 9937 & $59 \cdot 3$ & 10 \\
\hline$P_{1}^{2}$ & Both & IL & 7250 & 5057 & $79 \cdot 0$ & 22 \\
\hline$p_{1}$ & Both & BG & 24,638 & 22,012 & $29 \cdot 6$ & 9 \\
\hline
\end{tabular}

measurement. This is due in part to errors involved in use of the plainmeter and part to the slow response of the $X-Y$ plotter. The plotter was not able to accurately follow the chip formation since this is primarily a dynamic phenomena. This error is estimated at less than 10 per cent, however.

Noting Fig. 8, it is again seen that the general trend is for the spheres to require more energy than the pyramid which in turn requires more energy than the cones. The sharper cone seems to be the best indentor and the larger sphere seems to be the least successful of the lot. The granite is seen to require the largest energy expenditure followed by the parallel and perpendicular limestone. It is interesting to note that the specific energies required in granite are all relatively close to the lubricated compressive strength shown in Table 1. 


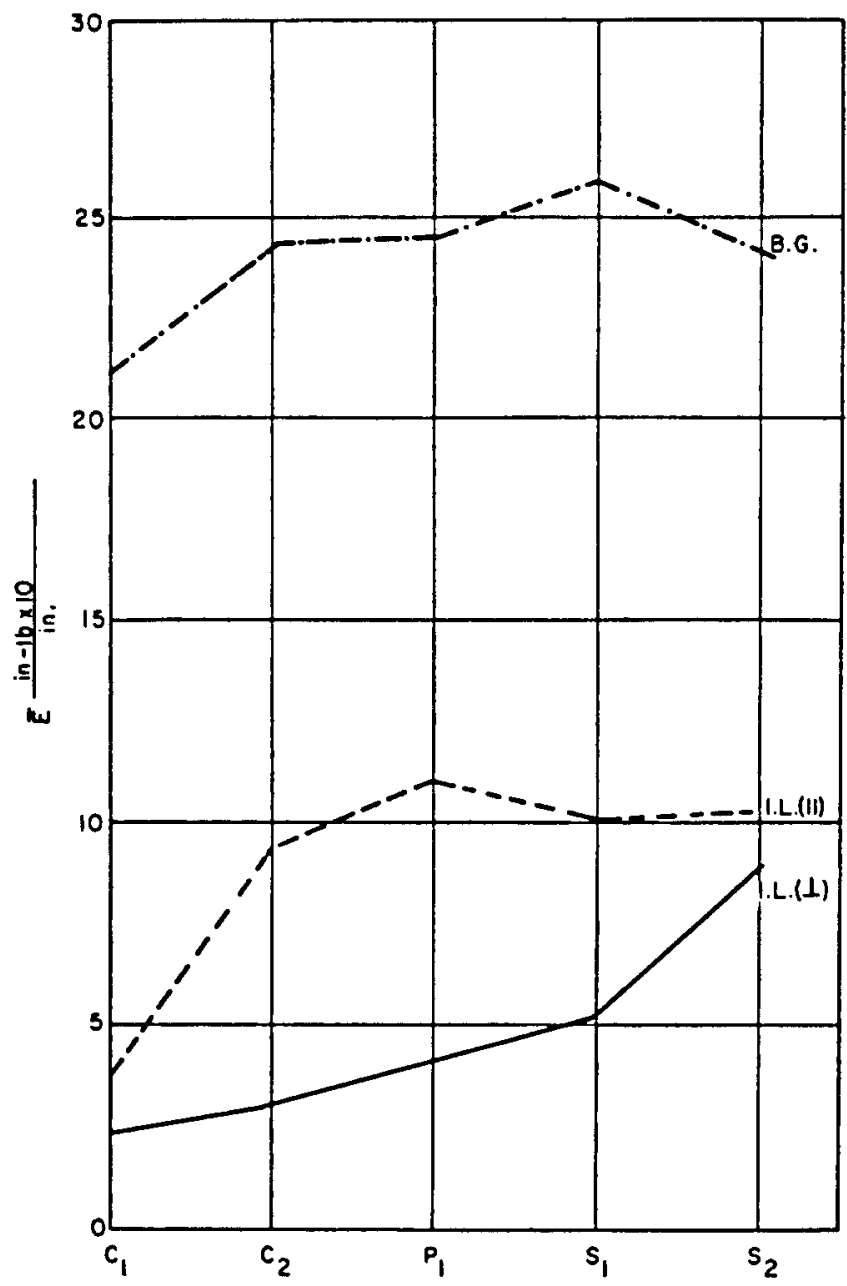

Fig. 8. Specific fracture energy.

\section{Projected stress at first chip}

It is conceivable that the advantage enjoyed by the cones and pyramid over the spheres might be simply due to the fact that for any given total load, sharper indentors have higher projected stresses than blunt indentors. It was therefore decided to compute the projected stress at the time of formation of the first chip in each test.

The projected stress, $\sigma_{p}$, is defined as the ratio of the first chipping load, $P_{1}{ }^{*}$, to the crosssectional area of the indentor measured at the intersection of the indentor and the free surface. For purposes of comparison, the projected stresses were non-dimensionalized by dividing by the compressive strength, $S_{c}$, of the rock. The values used were 28,000 psi for granite and $9000 \mathrm{psi}$ for limestone. The non-dimensionalized projected stress might be looked on as that stress necessary to initiate the chipping process, i.e. a "critical' stress.

An attempt was made to show the dependence of the non-dimensionalized projected stress (at formation of first chip) upon depth of penetration. A typical result is seen in Fig. 9, 


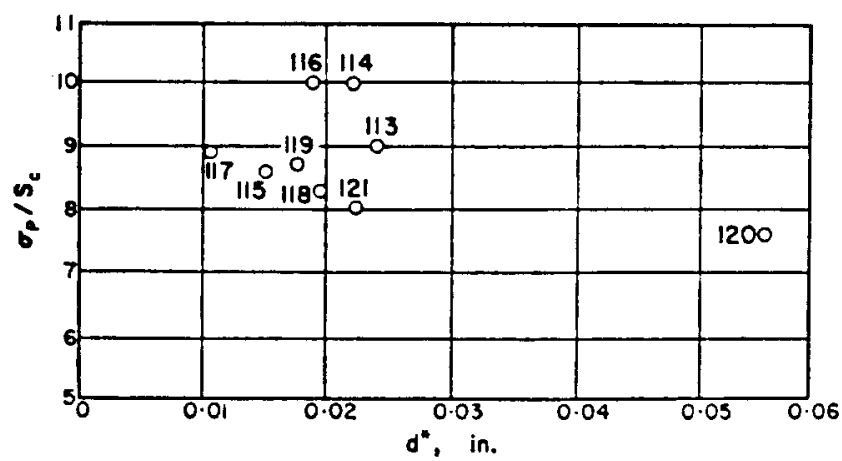

Fig. 9. Non-dimensionalized projected stress vs. $d^{*}$. (Barre Granite- $C_{1}$.)

which is a record of the penetration of granite by indentor $C_{1}$. The abcissa in Fig. 9 is the penetration depth at which the first chip occurred, $d_{1}{ }^{*}$. It is seen in this figure that the projected stress at the formation of the first chip seems to be independent of penetration, and remarkably constant at a level of around nine times the compressive strength. This is consistent with expectations from the theory of plasticity applied to rock indentation[5].

The non-dimensionalized projected stresses for all indentors in both rocks is presented in Table 5 and Fig. 10.

TAMle 5. Non-dimensionalized PROJECthd ChIPPING STRISS

\begin{tabular}{|c|c|c|c|c|c|c|}
\hline Indentor & $\begin{array}{c}\text { Axis of } \\
\text { penctration }\end{array}$ & $\begin{array}{c}\text { Rock } \\
\text { type }\end{array}$ & $\operatorname{Mean}\left(\sigma_{0} / S_{c}\right)$ & Median $\left(\sigma_{v} / S_{c}\right)$ & $\begin{array}{c}\text { Cocff. } \\
\text { variation }\end{array}$ & $\begin{array}{l}\text { Number } \\
\text { of tests }\end{array}$ \\
\hline$C_{\mathrm{I}}$ & $\perp$ & IL & $4 \cdot 13$ & $3 \cdot 82$ & $34 \cdot 5$ & 7 \\
\hline$C_{1}$ & 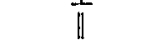 & IL & $4 \cdot 96$ & $4 \cdot 86$ & $11 \cdot 3$ & 3 \\
\hline$C_{\mathrm{t}}$ & Both & IL & $4 \cdot 38$ & $4 \cdot 11$ & $29 \cdot 4$ & 10 \\
\hline$C_{1}$ & Both & BG & $8 \cdot 80$ & $8 \cdot 70$ & $9 \cdot 0$ & 9 \\
\hline$C_{2}$ & 1 & IL & $6 \cdot 09$ & $6 \cdot 02$ & $18 \cdot 6$ & 4 \\
\hline$C_{3}$ & 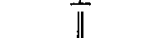 & IL & 6.87 & $6 \cdot 90$ & $16 \cdot 2$ & 4 \\
\hline$C_{3}$ & Both & IL & $6 \cdot 48$ & $6 \cdot 46$ & $18 \cdot 3$ & 8 \\
\hline$C_{2}$ & Both & BG & $9 \cdot 29$ & $9 \cdot 13$ & $8 \cdot 8$ & 8 \\
\hline$S_{1}$ & $\perp$ & IL & $4 \cdot 38$ & $4 \cdot 30$ & $10 \cdot 6$ & 7 \\
\hline$S_{1}$ & $\pi$ & IL & $4 \cdot 85$ & $4 \cdot 87$ & $18 \cdot 9$ & 6 \\
\hline$S_{l}$ & Both & IL & $4 \cdot 60$ & $4 \cdot 64$ & $16 \cdot 2$ & 13 \\
\hline$S_{1}$ & Both & BG & $8 \cdot 68$ & $9 \cdot 05$ & $10 \cdot 3$ & 8 \\
\hline$S_{2}$ & 1 & IL & $3 \cdot 88$ & $3 \cdot 80$ & $4 \cdot 4$ & 5 \\
\hline$S_{3}$ & $\frac{1}{\|}$ & IL & - & - & - & - \\
\hline$S_{2}$ & Both & IL & $3 \cdot 88$ & $3 \cdot 80$ & $4 \cdot 4$ & 5 \\
\hline$S_{2}$ & Both & BG & $5 \cdot 51$ & $5 \cdot 65$ & $4 \cdot 1$ & 5 \\
\hline$P_{1}$ & $\perp$ & IL & $4 \cdot 17$ & $3 \cdot 85$ & $28 \cdot 8$ & 5 \\
\hline$P_{1}$ & $\frac{1}{1}$ & IL & $3 \cdot 34$ & - & - & 1 \\
\hline$P_{2}$ & Both & IL & $4 \cdot 03$ & $3 \cdot 78$ & $28 \cdot 3$ & 6 \\
\hline$P_{1}$ & Both & BG & $9 \cdot 33$ & $10 \cdot 06$ & $32 \cdot 6$ & 9 \\
\hline
\end{tabular}

It is interesting to note that the large spherical indentor, $S_{\mathbf{2}}$, has a relatively low projected stress at chipping. Since this indentor will have the largest projected area at any given penetration, one might be led to assume that it is the magnitude of the force, and not the 


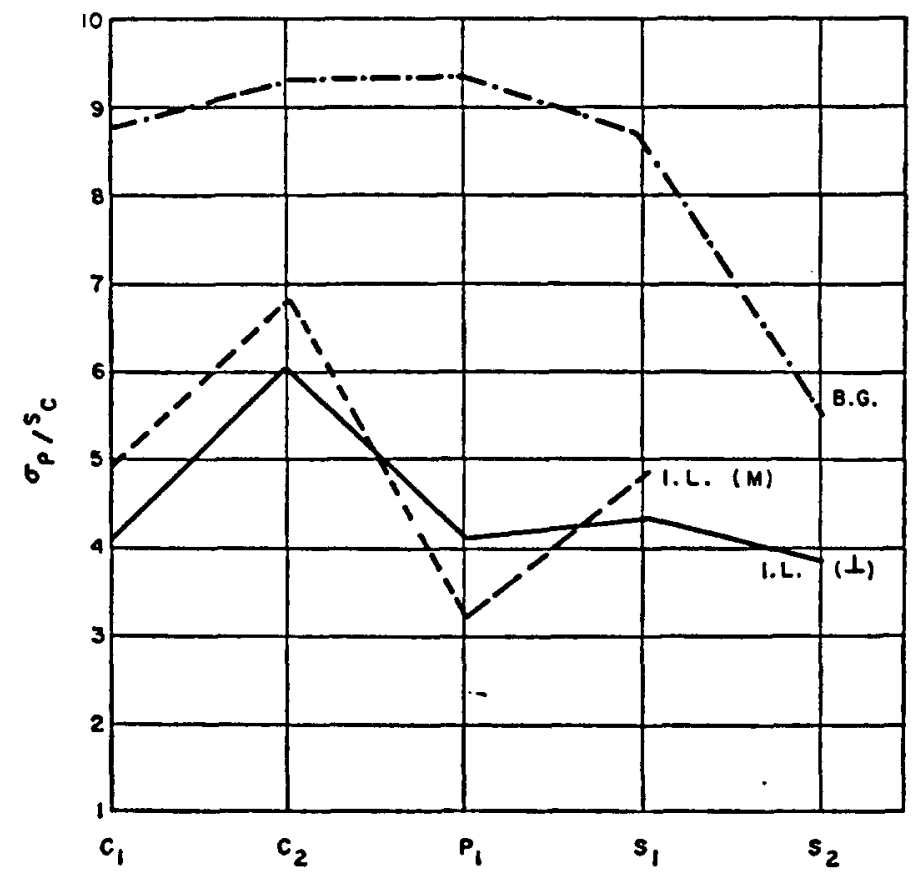

FIG. 10. Non-dimensionalized projected stress.

stress, which governs chipping. This conclusion would violate the relative values on Fig. 10 for $C_{1}$ and $C_{2}$, however.

\section{Crater geometry}

Prior to wire brushing, it was noted that a number of the craters, produced in tests which did not progress to the first chip, were geometrically similar to the indentors which produced them. Further, in many tests where chipping did occur, the first chip exhibited some similarity to the indentor. With these exceptions, however, an assumption of geometric similarity, especially from chip to chip, cannot be verified by the experimental results.

The chips in multi-chip tests did not, in general, exhibit geometric similarity or even axisymmetry. After wire brushing, the final craters exhibited random geometries which seemed to be influenced more by local rock anomalies than by the indentor geometry.

\section{INDENTOR PENETRATION ANALYSIS}

The preliminary theory of static penetration by a rigid wedge developed by PAUL and SIKARSKIE[1] can be directly extended to three-dimensional indentors such as cones and pyramids if certain assumptions are made.

Conical indentors will be assumed to produce chips which are essentially conical shells. A pyramid indentor will be assumed to produce pyramid shaped chips and the stress concentrations at the corners of the pyramid will be neglected as they will be assumed to produce only local failure, such as plastic flow or cracks. As was done in the previous theory, geometric similarity from one chip to the next will also be assumed, even though this assumption cannot be verified by the experimental results.

$\operatorname{nocx} 5 / 5-1$ 


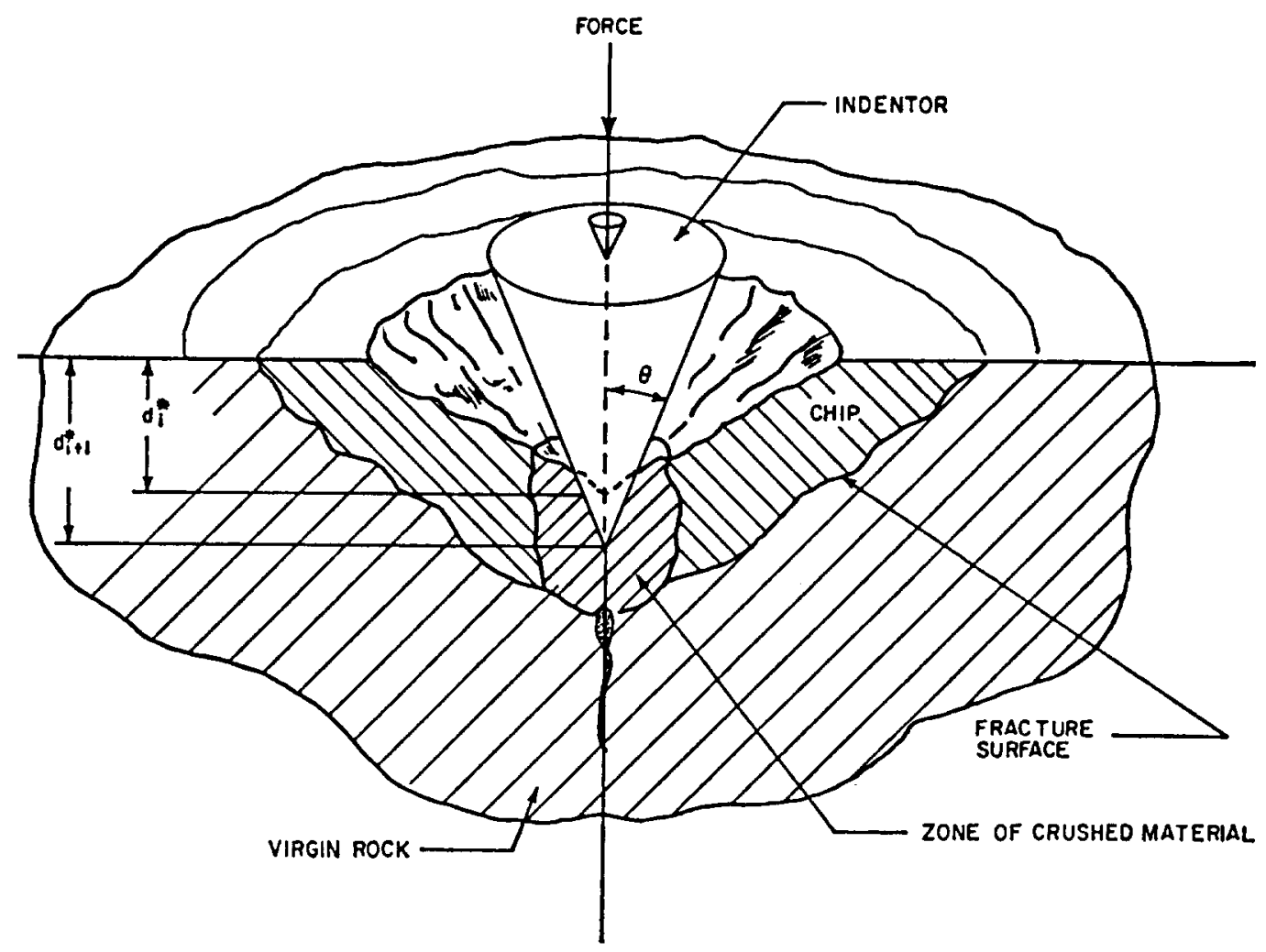

Fig. 11. Indentation of rock-like material by threc-dimensional penetrator.

Let us consider a sharp indentor, either a cone or pyramid, shown in Fig. 11. When the indentor reached a penetration of $d_{1}{ }^{*}$ the $i$-th chip was broken away from the virgin rock. As the indentor continues to penetrate it will cause crushing in a zone around its apex until it reaches a penetration of $d_{1+1}$ at which time a fracture surface will be generated from the indentor apex to the free surface of the rock and thus the $(i+1)$ st chip will be created. The mathematical idealization of this process is shown in Fig. 12 where it is noted that the indentor geometry is specified by the semi-vertex angle $\theta$ and the failure surface geometry is specified by the failure angle $\psi$.

If we consider the averaged force equilibrium of the indentor just as the $(i+1)$ st chip is formed, and assume that the indentor rock interface is frictionless, then

$$
P_{i+1}^{*}=s_{t+1} a_{i+1} \sin \theta
$$

where

$P^{*}{ }_{1+1}=$ load acting on the indentor just as the $(i+1)$ st chip forms

$s_{1+1}=$ averaged normal stress imparted by the rock to the indentor

$a_{1+1}=$ area of the interface between the rock and the indentor.

Now considering the equilibrium of the $(i+1)$ st chip, it is seen that

$$
\begin{aligned}
& s_{t+1} a_{t+1} \cos (\psi+\theta)=\bar{\tau} A \\
& s_{i+1} a_{t+1} \sin (\psi+\theta)=\bar{\sigma} A
\end{aligned}
$$




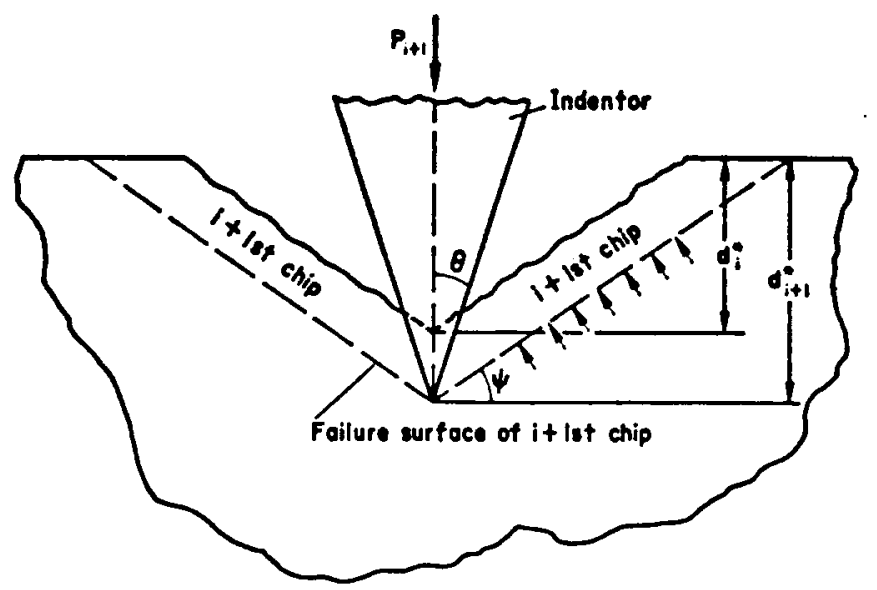

Fig. 12. Mathematical idealization of the $i+1$ st chip.

where

$A \quad=$ failure surface area

f $\quad=$ average shear stress over the failure surface

$$
=\frac{1}{A} \int \tau \mathrm{d} A
$$

$\overline{\mathbf{o}}$

$=$ average normal stress over the failure surface

$$
=\frac{1}{A} \int \sigma \mathrm{d} A
$$

Hence

$$
\begin{aligned}
& \tau=\frac{P_{i+1}^{*} \cos (\psi+\theta)}{A \sin \theta} \\
& \bar{\sigma}=\frac{P_{i+1}^{*} \sin (\psi+\theta)}{A \sin \theta}
\end{aligned}
$$

If failure occurs simultaneously along the entire failure surface, the modified Coulomb-Mohr criteria[1] require that

$$
\bar{\tau}-\mu \overline{\boldsymbol{\sigma}}=c
$$

where

$$
\begin{array}{ll}
\mu & =\text { coefficient of internal friction }=\tan \phi \\
\phi & =\text { angle of internal friction (material constant) } \\
c & =\text { cohesive strength material constant. }
\end{array}
$$

From equations (3) it is seen that at failure

$$
{ }^{*}-\mu \bar{\sigma}=\frac{P_{i+1}^{*} \cos (\psi+\theta+\phi)}{A \sin \theta \cos \phi} \text {. }
$$


Since $\psi$ must be that angle which maximizes this expression, it is seen that

$$
\frac{\mathrm{d}(\boldsymbol{F}-\mu \bar{\sigma})}{\mathrm{d} \psi}=\frac{P_{i+1}^{\bullet}}{\sin \theta \cos \theta}\left[\cos (\psi+\theta+\phi) \frac{\mathrm{d}}{\mathrm{d} \psi}\left(\frac{1}{A}\right)-\frac{\sin (\psi+\theta+\phi)}{A}\right]=0 .
$$

This yields

$$
\tan (\psi+\theta+\phi)=\frac{\mathrm{d}}{\mathrm{d} \psi}\left(\frac{1}{A}\right)
$$

or

$$
\theta+\phi=-\psi+\tan ^{-1}\left[A \frac{\mathrm{d}}{\mathrm{d} \psi}\left(\frac{1}{A}\right)\right]
$$

where

$$
A= \begin{cases}\pi d_{i+1}^{* 2} \frac{\cos \psi}{\sin ^{2} \psi} & \text { for a cone } \\ 4 d_{i+1}^{* 2} \cot \psi & \text { for a pyramid. }\end{cases}
$$

Combining equations (7) and (8) will result in a solution of the form

$$
\psi=F(\theta, \phi) \text {. }
$$

That is, the failure angle $\psi$ is a unique function of the semi-vertex angle of the indentor and the angle of internal friction of the material. Equation (9) has been solved graphically.

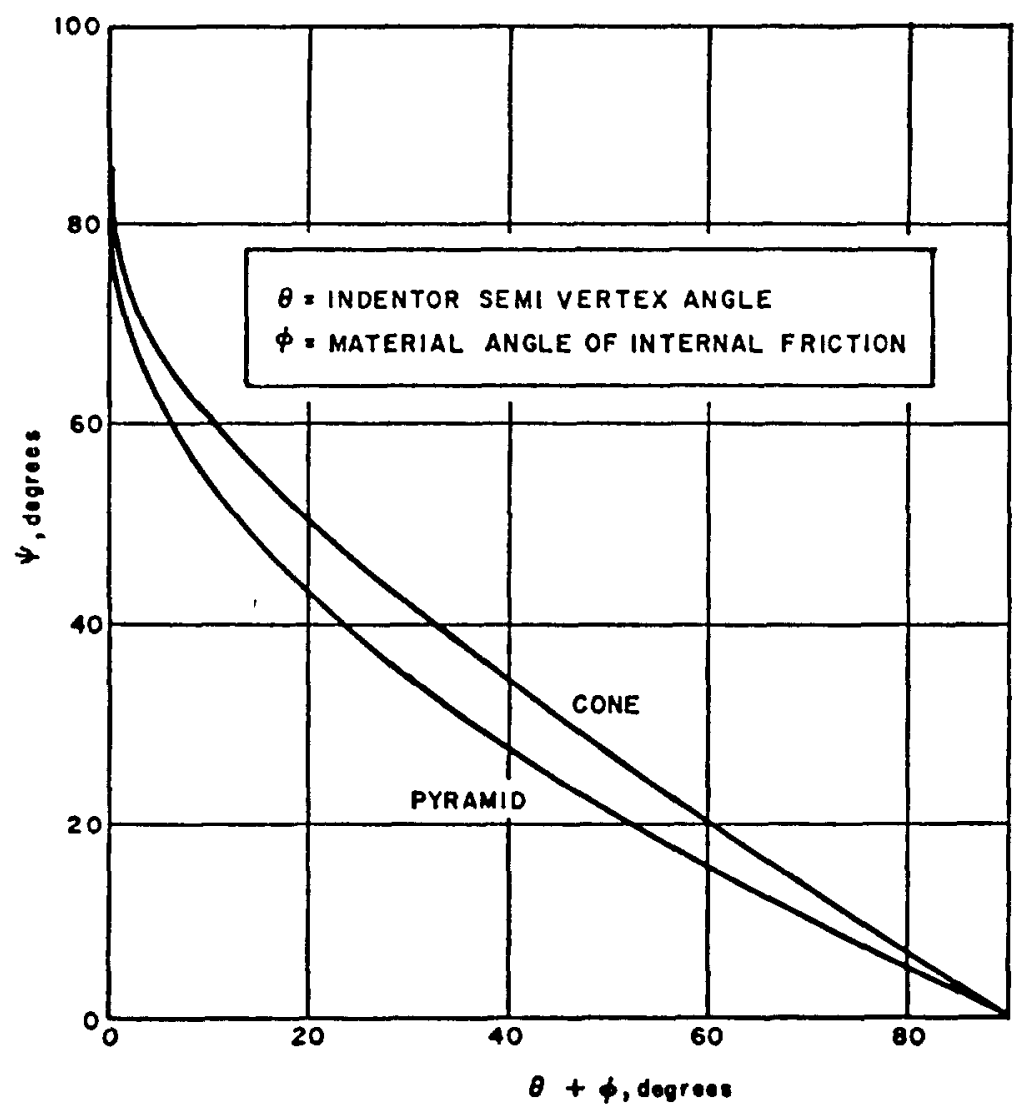

Fio. 13. Failure angle $(\psi)$ vs. $(\theta+\phi)$. 
The results are shown in Fig. 13. It is now possible to completely eliminate all consideration of the failure angle, since equation (9) will yield

$$
\frac{\cos (\psi+\theta+\phi)}{A}=\frac{f(\theta, \phi)}{d_{t+1}^{c 2}}
$$

where the function $f(\theta, \phi)$ is plotted in Fig. 14.

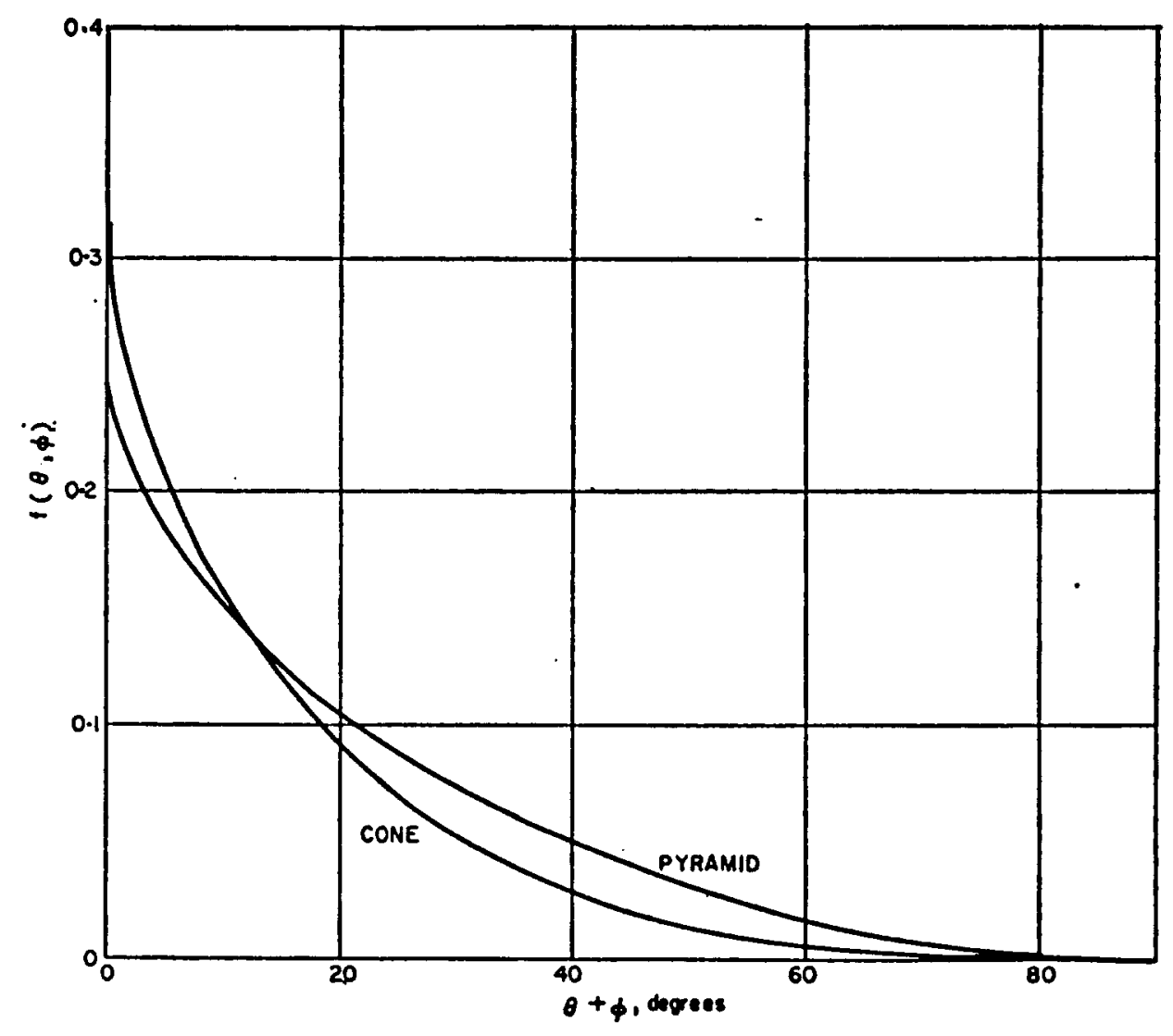

Fio. 14. $f,(\theta, \phi)$ vs. $\theta+\phi$.

Combining equations (4), (5) and (10) produce

$$
\frac{P_{i+1}^{*} f(\theta, \phi)}{d_{1+1}^{* 2} \sin \theta \cos \phi}=c
$$

or

$$
\frac{P_{i+1}^{*}}{d_{i+1}^{*}}=\frac{c \sin \theta \cos \phi}{f(\theta, \phi)}=K
$$

From equation (12) it is seen that for given material properties $\left(\phi, S_{c}\right)$ and indentor angle $(\theta)$ the ratio of load to the square of the penetration, just as a chip is formed, is constant. 
This implies that the chipping points must lie along the curve $P^{*} 1+1=K d^{* 2} 1+1$ on a forcepenetration curve. By comparison, PAUL and SiKARSKIE [1] have shown that the chipping points lie along a straight line for a wedge indentor.

As was seen in Section 3, it is consistent with experimental results to assume a separate linear relationship between the applied force and the penetration during each crushing phase. Thus

$$
P_{t+1}=k_{t}\left[d_{t+1}-d_{t}^{*}\right] \text {. }
$$

At the formation of the $(i+1)$ st chip this becomes

$$
P_{i+1}^{*}=k_{1}\left[d_{1}^{*}-d_{i}^{*}\right] \text {. }
$$

Combining equations (12) and (14) results in the recurrence relations

$$
d_{i+1}^{*}=\frac{k_{1} \pm \sqrt{ }\left(k_{i}^{2}-4 K k_{i} d_{i}^{*}\right)}{2 K}
$$

and

$$
P_{i+1}^{*}=\frac{k_{i}\left[k_{\imath}-2 K d_{i}^{*} \pm \sqrt{ }\left(k_{i}^{2}-4 K k_{\imath} d_{i}^{*}\right)\right]}{2 K} .
$$

Since these equations can yield complex solutions, they imply the possibility that chipping will cease at some critical penetration. From equation (15) this penetration is found to be

$$
d_{\text {icr }}^{*}=\frac{k_{i}}{4 K}
$$

Gcometrically, this is equivalent to noting the possibility that the straight line which represents a particular crushing phase on the force-penetration curve may never intersect the quadratic curve which represents the chipping point envelope. It should be noted that this possibility occurs because of the assumption of a linear crushing law, which was based upon the experimental results.

\section{Volume of rock removed and associated energies}

From Fig. 12, it is seen that the total volume of rock removed immediately after the $i$-th chip breaks out is

$$
V=\left\{\begin{array}{l}
\frac{\pi\left(d_{i}^{*}\right)^{3} \cot ^{2} \psi}{3} \text { cone } \\
\frac{4\left(d_{t}^{*}\right)^{2} \cot ^{2} \psi}{3} \text { pyramid }
\end{array}\right.
$$

The encrgy required to break out this volume is dependent upon the nature of the loading, that is, the force-penetration curve. Figure 15 shows a typical hypothetical loading curve which exhibits a monotonically increasing load during crushing followed by a sudden decrease in load when a chip is formed and a subsequent return to another crushing phase. This typical curve is bounded by the idealized constant load and instant unload tests. In the constant load test, the chipping load, $P_{l}$, is maintained on the indentor until the next crushing phase begins. In the instant unload test the load on the indentor vanishes as each chip is formed and each crushing phase begins again from a zero load. 


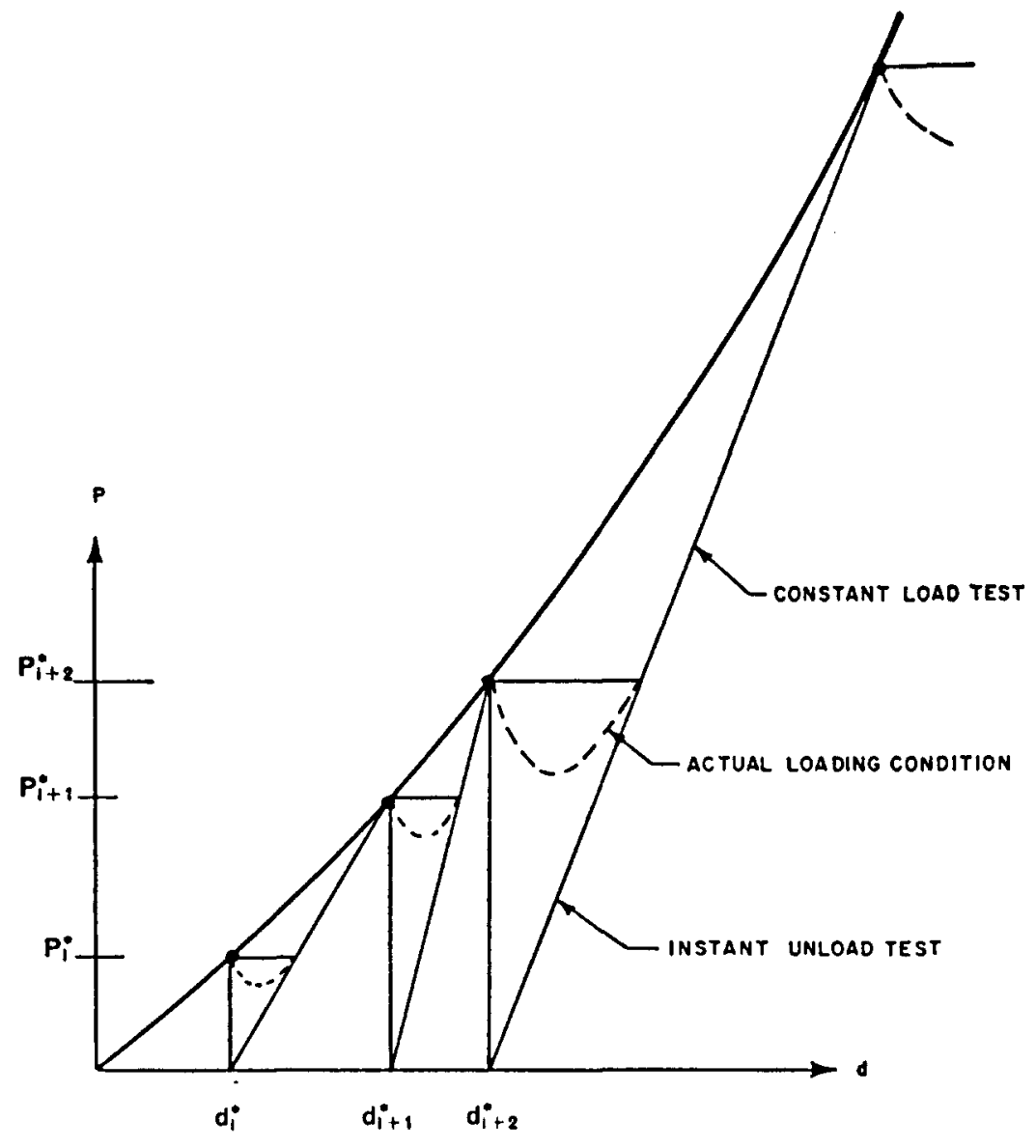

FiG. 15. Hypothetical loading curve. (Typical.)

In the instant unload test, assuming a linear crushing curve, the total energy expended at the time of formation of the $i$-th chip is

$$
E_{a}=\sum_{n=1}^{1} \mathbb{2}\left[d_{n}^{*}-d_{n}^{*}-1\right] p_{n}^{*}
$$

Combining equations (12) and (19)

$$
E_{a}=\sum_{n=1}^{1} \frac{K}{2}\left[\left(d_{n}^{*}\right)^{3}-\left(d_{n}^{*}\right)^{2} d_{n-1}^{*}\right]
$$

The specific fracture energy, the energy required to remove a unit volume of rock is then given by

$$
\vec{E}_{\bullet}=\frac{E_{a}}{V} .
$$


For the constant load test simple geometric considerations yield

$$
\begin{aligned}
E_{0} & =\sum_{n=1}^{1} \frac{1}{2}\left[d_{*}^{*}-d_{*-1}^{*}\right] p_{n}^{*}+\sum_{n=1}^{1-1} \frac{1}{2}\left[d_{n}^{*}-d_{n-1}^{*}\right] p_{*}^{*} \\
& =\sum_{n=1}^{i=1} K\left[\left(d_{n}^{*}\right)^{3}-\left(d_{n}^{*}\right)^{2} d_{n-1}^{*}\right]+\frac{K}{2}\left[\left(d_{i}^{*}\right)^{3}-\left(d_{i}^{*}\right)^{2} d_{i-1}^{*}\right]
\end{aligned}
$$

Again the specific fracture energy is given by

$$
\bar{E}_{0}=\frac{E_{0}}{V}
$$

where $V$ is given by equations (18).

Equations (20) and (22) can be rewritten in terms of any chipping penetration, $d_{1}^{*}$, by using the recurrence relation, equation (15). Since this recurrence relation is not linear, as it was in the two-dimensional theory, the specific fracture energy for either type of loading should generally be a function of penetration.

\section{Force-penetration relationship at chipping}

In the theory presented in this section it was shown that the locus of all points which represent chipping on the force-penetration curve is the envelope curve $P_{1}=K\left(d_{1}^{*}\right)^{2}$.

Since at least three chipping points in a given test are necessary to show a quadratic relation, and since very few tests in the experimental program included more than two chips, it is not possible to make meaningful statements about the envelope. Nevertheless it is interesting to examine threc of the multi-chip tests.

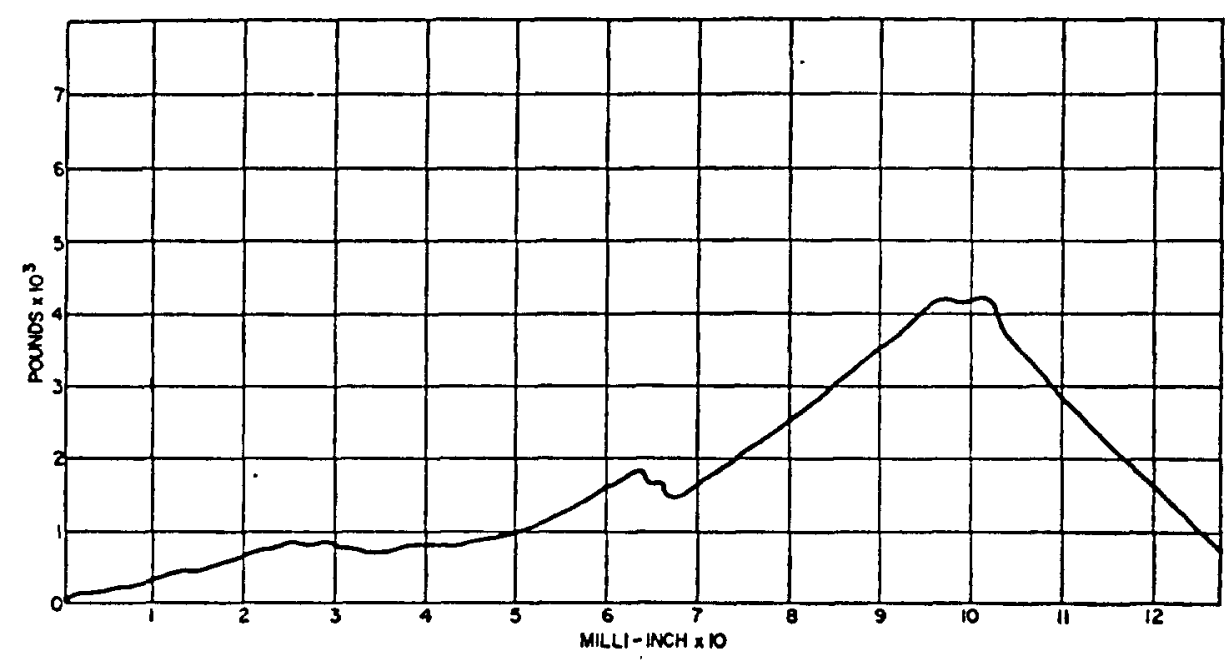

FIG. 16. Force vs. penetration-indentation of Indiana Limestone by $C_{\mathbf{2}}$. 


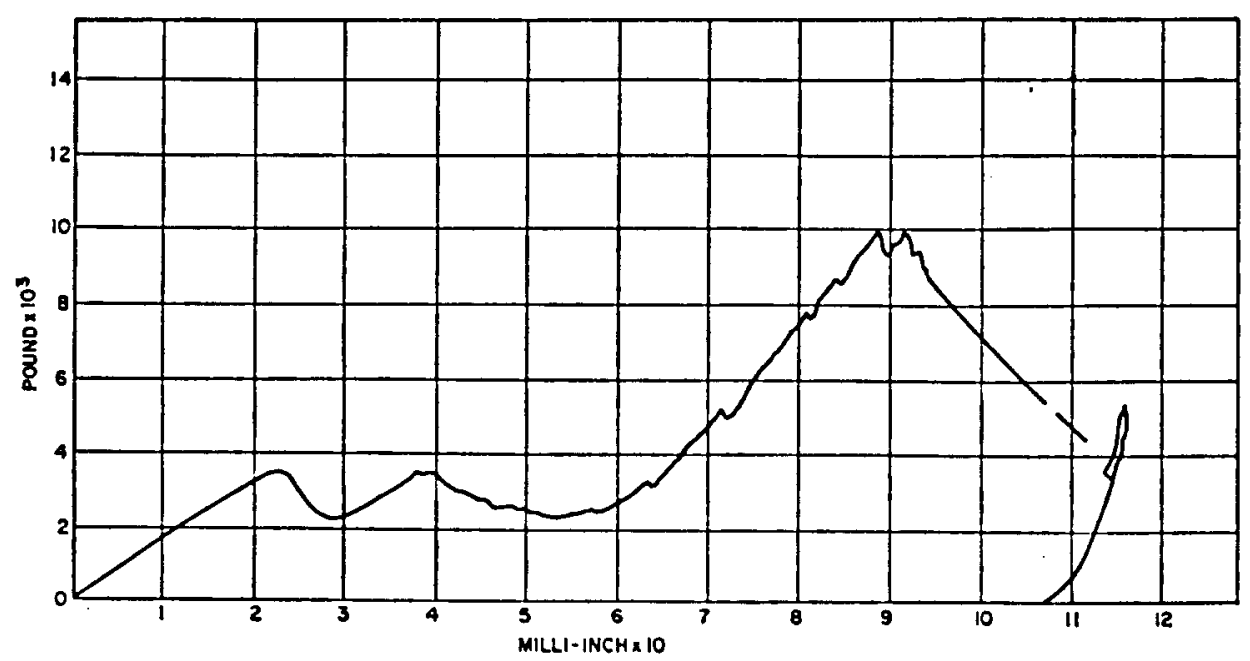

Fio. 17. Force vs. penetration-indentation of Barre Granite by $C_{1}$.

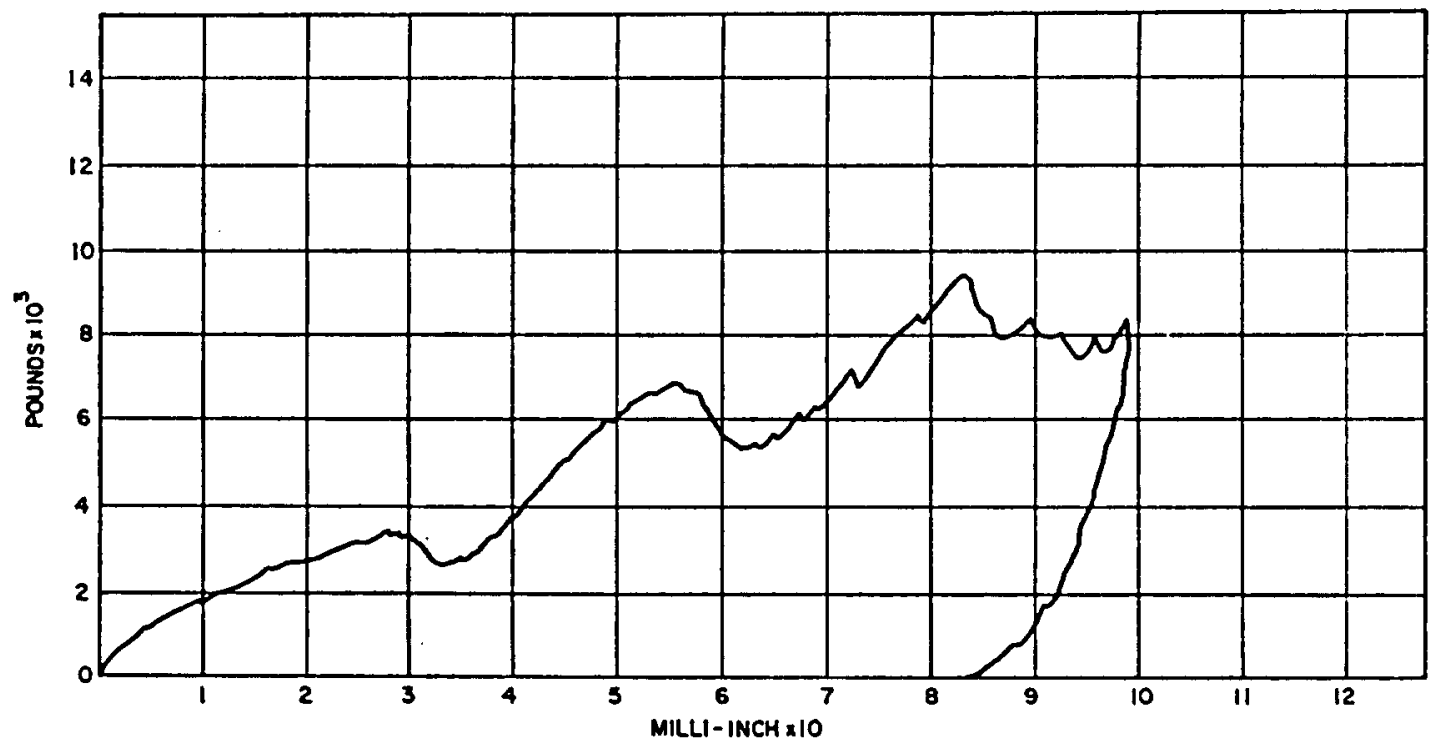

Fio. 18. Force vs. penetration-indentation of Barre Granite by $C_{2}$. 
The first of these tests is shown in Fig. 16. This is a record of the penetration of limestone by indentor $C_{2}$. The chipping peaks in this figure are seen to lie along a non-linear envelope. A similar curve is seen for the penetration of granite by indentor $C_{1}$, in Fig. 17. However, the envelope for the force-penetration curve seen in Fig. 18, which was also made by $C_{1}$ indenting granite, is quite adequately specified by a linear relation.

\section{CONCLUSIONS}

The experimental program has provided numerical data for such material constants as initial and post-chipping crushing slopes, and parameters which appear to be constants, such as specific fracture energy and projected stress at first chip. The reliability of these values, as indicated by the associated coefficients of variation, seem reasonable in view of the large scatter normally expected when working with heterogeneous materials such as rock. The values for the crushing slopes seem to be particularly reliable.

It is of interest to note that the scatter appears to be about the same for both Indiana limestone and Barre granite. From all appearances the Indiana limestone is considerably more homogeneous than Barre granite which should tend to reduce scatter. It is felt, however, that flaws are created in the crushing phase of even fairly homogeneous brittle materials* such that initial homogeneity plays a far lesser role than it would in different types of tests.

Comparison of indentors. Although some of the evidence is somewhat contradictory, the experimental results tend to indicate that the sharper cone, $C_{1}$, is the best indentor, following in order of success the second cone $C_{2}$, the pyramid $P_{1}$, the smaller sphere $S_{1}$, and finally by the larger sphere $S_{2}$. This order is seen in the crushing plase, as indicated by the initial and post-chipping crushing slopes, and in the total specific fracture energy. This relative inferiority of spheres to sharper indentors is in agreement with the conclusions of HARTMaN[2] which were based upon drop tower tests.

This conclusion should not be taken as a mandate to immediately replace all spherical indentors on drilling devices by pyramids or cones. No consideration has been given in this program to the effects of indexing, stress concentrations, or indentor wearing, all of which are very important in practical devices. Nevertheless, it should be noted that the spherical indentor was the least successful of the geometries investigated.

It is interesting to note from Fig. 8 that the difference between indentors is not as great in granite as it is in limestone. Thus, one can conclude that, compared to a sharper indentor bit, a spherical indentor button bit might perform better in harder rocks, such as granite, than it would in softer rocks such as limestone. This conclusion is also in agreement with HARTMAN[3].

The curves in Fig. 8 also show a significant difference between the specific fracture energies for penetrations made perpendicular to the bedding plane in limestone and penetrations made parallel to the bedding plane. This implies that the drilling rate in such rocks depends upon the orientation of the drill to the rock. For Indiana limestone, the experimental results indicate that a higher drilling rate would be obtained when drilling normal to the bedding planes.

Comparison of 3-dimensional indentors with wedges

A separate series of quasi-static penetration experiments was also run under the same conditions on both Indiana limestone and Barre granite using wedges of varying wedge-angle

- No averaging mechanism such as plastic flow exists in this case. 
and wedge-tip radius*[4]. The Indiana limestone results in this series of tests are of somewhat limited use quantitatively since the bedding direction was unknown in the samples used, however, it is useful to compare the results qualitatively to the results for the threedimensional indentors.

The mean specific fracture energy (energy necessary to remove a unit volume of rock) for all tests ranged from $4500 \mathrm{psi}$ to $8500 \mathrm{psi}$ for Indiana limestone and 22,000 psi to 32,000 psi for the Barre granite and tended to the larger values for the larger wedge angles and the smaller tip radii. Comparison of these results with Table 4 indicates that threedimensional indentors may or may not be more effective depending on the geometries. In any event the sharper conical indentor gives the lowest specific energy of all.

It is of interest to note that in the wedge experiments there appears to be a universal 'critical stress' (non-dimensional projected stress) necessary to initiate the chipping process. The mean of this critical stress was approximately equal to 6 and within fairly large experimental scatter held for all wedge angles, wedge tip radii and rock type. Figure 10 is a comparable plot for the three-dimensional indentors. The results for Indiana limestone compare favorably with the wedge results; however, the Barre granite results are higher. It is also of interest to compare the wedge results with those of CHEATHAM[5]. In that case, the wedge is penetrating a plastic rock having a Coulomb-Mohr yield envelope. For an internal friction angle of $\phi=0^{\circ}$ a non-dimensional projected stress of approximately two is necessary for the wedge to penetrate $\dagger$. This corresponds to our crushing phase and is somewhat lower than our experimental results indicate.

\section{Comparison between theory and experiments}

The extension of the theory of SiKarskie and PAUL [1] which was developed in Section 4 resulted in the conclusion that just prior to the formation of any chip, the load on the indentor is proportional to the square of the distance of penetration. Furthermore, as was shown in equation (12), the constant of proportionality is independent of penetration.

Further, the theory indicated that specific fracture energy should be a function of penetration since the recurrence relation between successive chips, equation (15), is not linear. It is recalled that the two underlying assumptions in the theory are geometric similarity from chip to chip, and the applicability of an averaged stress failure criterion. This has been shown by Sikarskic and Paul to be equivalent (in the case of the wedge) to assuming a simultaneous failure along the entire 'initial' failure surface.

As was noted in Section 4, the experimental results are not conclusive with regard to proving or disproving the existence of a quadratic chipping envelope. Deeper tests which could have led to additional multi-chip results, were precluded by sample splitting considerations.

With regard to the specific fracture energy, the scatter in the experimental results eliminated the possibility of experimentally verifying the relationship between the specific energy and penetration.

In spite of all these difficulties, it is possible to make some statements regarding the qualitative theoretical predictions. First, the three-dimensional indentors have exhibited

Wedge angles of $60^{\circ}, 90^{\circ}, 120^{\circ}$, and wedge tip radii of 0.01 in., 0.05 in., $0.10 \mathrm{in}$. were used in these tests.

$\dagger$ The projected stress for $\phi=0^{\circ}$ is also a weak function of wedge angle, remaining approximately equal to 2 over wedge angles from $60^{\circ}-120^{\circ}$. For larger angles Cheatham's results come into better agreement with the present experiments, however, in view of the high mean stresses in the vicinity of the wedge tip. $\phi$ should be quite small. 
non-linear chipping envelopes. This was generally not the case for two-dimensional indentors such as wedges[4]. It is recalled that the combination of a quadratic chipping envelope and a linear crushing curve led to the possibility, shown in equation (17), that only crushing could occur after the indentor reached a certain critical penetration.

Second, the assumption of geometric similarity does not seem to be valid after the first chip is formed. Thus, the theory cannot be expected to yield accurate quantitative results for three-dimensional indentors. It can, however, provide a useful qualitative tool for visualizing the fracture caused by a three-dimensional indentor.

Acknowledgements-The authors wish to acknowledge the many helpful suggestions of Dr. BuRTON PAUL and the support of the Ingersoll-Rand Research Center at which this work was performed.

\section{REFERENCES}

1. Paul B. and Sikarskie D. L. A preliminary theory of static penetration by a rigid wedge into a brittle material. Trans. Am. Soc. Mech. Engrs 372-383, December (1965).

2. Hartman H. L. Basic studies of percussion drilling. Min. Engng, N. Y. 68-75, January (1959).

3. HaRtMan H. L. Crater geometry relations in percussive drilling. Mine Quarry Engng 530-536, December (1962).

4. Strarskie D. L. Experiments on Wedge Indentation in Rocks, TN-262, Ingersoll-Rand R\&D Center, May (1966).

5. Cheatham J. B. An Analytical Study of Rock Penetration by a Single Bit Tooth, Proceedings of the Eighth Annual Drilling and Blasting Symposium, University of Minnesota (1958). 